\title{
Enhanced recovery after surgery of patients undergoing radical cystectomy for bladder cancer
}

\author{
Luck Hee Sung ${ }^{1}$, Hyeong Dong Yuk ${ }^{2}$ \\ ${ }^{1}$ Department of Urology, Inje University Sanggye Paik Hospital, Seoul, Korea; ${ }^{2}$ Department of Urology, Seoul National University Hospital, Seoul, \\ Korea \\ Contributions: (I) Conception and design: HD Yuk; (II) Administrative support: LH Sung; (III) Provision of study materials or patients: LH Sung; (IV) \\ Collection and assembly of data: LH Sung; (V) Data analysis and interpretation: LH Sung; (VI) Manuscript writing: All authors; (VII) Final approval \\ of manuscript: All authors. \\ Correspondence to: Hyeong Dong Yuk, MD. Department of Urology, Seoul National University Hospital, 101 Daehak-ro, Jongno-gu, Seoul 110-744, \\ Korea. Email: hinayuk@naver.com.
}

\begin{abstract}
Radical cystectomy $(\mathrm{RC})$ is the standard treatment for patients diagnosed with muscle invasive bladder cancer, but is associated with significant morbidity and long hospital stays. Enhanced recovery after surgery (ERAS) is based on a variety of interventions during the peri-treatment stage. It is designed to improve morbidity, enhance recovery, and reduce hospital stays after RC. The study provides an overview of the key elements of the ERAS protocol recommended for patients undergoing RC and directions for further research. We have analyzed the rationale for 15 key elements related to the ERAS protocol: preoperative patient counseling and education, preoperative medical optimization and nutrition, mechanical bowel preparation, preoperative fasting and carbohydrate loading, pre-anesthetic medication, thromboembolic prophylaxis, minimally invasive surgical approach, resection-site drainage, preventing intraoperative hypothermia, perioperative fluid management, perioperative analgesia, urinary drainage, prevention of postoperative ileus, nausea and vomiting, early oral feeding, and early mobilization. Several studies have shown that ERAS improves the recovery of RC patients. Evidence suggests that ERAS facilitates the recovery of RC patients. However, additional randomized controlled studies or large prospective studies are needed to demonstrate the effectiveness of ERAS in RC patients.
\end{abstract}

Keywords: Bladder cancer; enhanced recovery after surgery (ERAS); perioperative care; radical cystectomy (RC)

Submitted Oct 30, 2019. Accepted for publication Mar 04, 2020.

doi: $10.21037 /$ tau.2020.03.44

View this article at: http://dx.doi.org/10.21037/tau.2020.03.44

\section{Introduction}

Enhanced recovery after surgery (ERAS) was first introduced in 1997 by Kehlet in colorectal surgery as part of a multimodal approach to postoperative recovery (1). In 2005, the ERAS study group published an evidence-based ERAS protocol for colorectal cancer patients (2). According to the protocol, a quick return to normal function may reduce postoperative pain and stress, and reduce the rate of postoperative complications. In the protocol, ERAS does not entail preoperative bowel preparation and fasting, or intake of diluted carbohydrates and water until $2 \mathrm{~h}$ before surgery. Any fluid overload during the entire procedure is avoided. The body temperature is maintained, and non-opioid analgesics are used. No postoperative decompression or drainage is attempted using a nasogastric tube. The urethral catheter is removed early and physical mobilization is resumed early. The patient is advised to take postoperative diet early $(2,3)$. In a metaanalysis of six randomized controlled trials (RCTs) for ERAS in colorectal surgery, ERAS reduced the complications by $50 \%$ and the hospitalization period by 2.5 days without any difference in re-entry rate or mortality. This study provided the basis for level 1 evidence of ERAS application in colorectal surgery (4). Since then, ERAS has been used in various 
Table 1 Summary of preoperative, intraoperative, and postoperative ERAS items

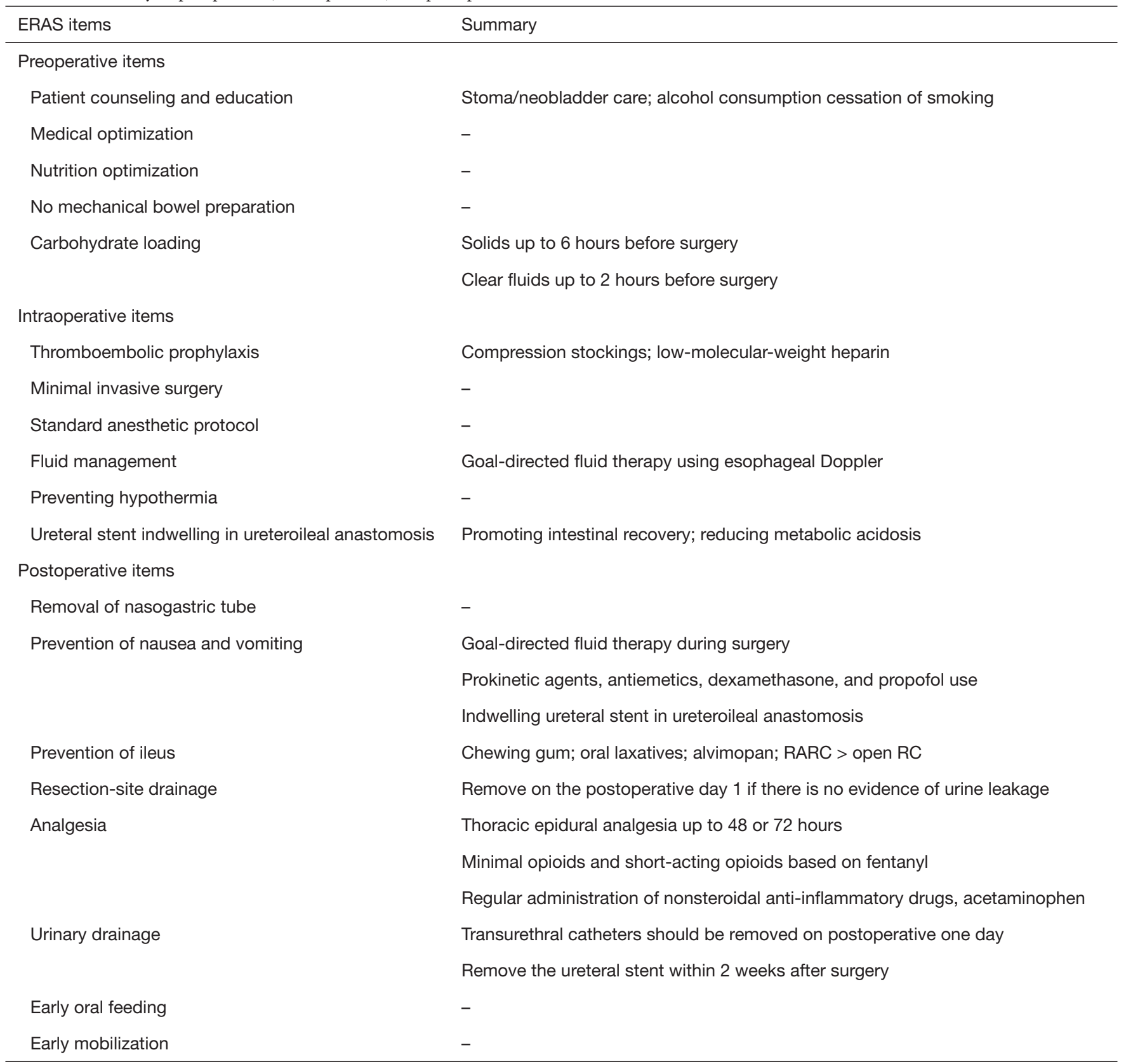

ERAS, enhanced recovery after surgery; RARC, robot-assisted radical cystectomy.

surgical procedures including those related to heart, lung, gynecologic oncology, breast reconstruction, head and neck oncology, liver and pancreas, and gastrointestinal tract (5-10). In urology, ERAS has also been used in cystectomy of patients with bladder cancer (4). Cystectomy is conducted to treat complications such as intestinal resection and anastomosis for urinary diversion and associated postoperative complications.
Cystectomy involves intestinal resection and anastomosis for diversion. ERAS is used to managed the complexity of these procedures and the high incidence of complications related to surgery. We reviewed the ERAS protocol (Table 1) of patients who underwent cystectomy, and analyzed the evidence for each ERAS component to assess the overall effectiveness of the intervention. 


\section{Preoperative patient counseling and education}

Preoperative counseling and education of patients and caregivers reduces patient and caregiver fears and anxieties, enhances postoperative recovery and reduces hospital stays (11-14). In addition to surgical procedure and hospitalization information, detailed information about preoperative care, discharge criteria, multiple methods for ERAS, multiple catheters, and management of stoma and neobladder should be provided $(13,14)$. Such consulting and education can encourage patients, improve recovery and reduce complications (13-15).

\section{Preoperative medical optimization and nutrition}

Preoperative assessment is important for patients undergoing radical cystectomy (RC). Evaluation and optimization of multiple factors and medical conditions that affect patient's recovery after surgery are needed. Preoperative considerations include high blood pressure, diabetes, anemia, various comorbidities, physical exercise, smoking, and drinking $(4,16)$. Preoperative physical activity and exercise can expedite recovery (17). Smoking cessation in colorectal surgery reduces postoperative complications and hospitalization rates. However, pulmonary complications often occur in case of sudden smoking cessation just before surgery for long-term smokers. To minimize these complications, smoking cessation at least 1 month before surgery is recommended $(18,19)$. Abstinence from alcohol consumption starting 1 month before surgery reduces postoperative complications (20). Preoperative malnutrition is associated with a high risk of postoperative complications and mortality (21). To reduce complications, appropriate management is necessary at least two weeks before surgery (21).

\section{Mechanical bowel preparation}

Randomized controlled studies and meta-analyses have reported that mechanical bowel preparation does not decrease morbidity, hospital stay, or bowel function recovery time in colorectal surgery (22-24). Mechanical bowel preparation can cause dehydration, electrolyte imbalance, intestinal obstruction, and preoperative physical stress in the patient (24). However, a recent study involving robot-assisted RC (RARC) with intracorporeal urinary diversion reported that undigested vegetables may leak into the peritoneum during surgery, so it is necessary to avoid vegetable intake before surgery (25).

\section{Preoperative fasting and carbohydrate loading}

Preoperative carbohydrate loading has been shown to reduce thirst, maintain lean body mass and muscle strength, and help restore early bowel function $(15,26)$. A metaanalysis of patients undergoing open abdominal surgery reported a significant reduction in hospital stay when they were exposed to carbohydrates before surgery (26). It is also effective in reducing postoperative insulin resistance and hyperglycemia, especially in diabetic patients undergoing surgery $(15,26)$.

Preoperative fasting entails fasting from midnight to reduce the risk of pulmonary aspiration during surgery. However, the European Society of Anesthesiology reports that solid foods can be consumed up to two to six hours before surgery without any risk of complications due to anesthesia in such patients (27).

\section{Pre-anesthetic medication}

Preoperative anti-anxiety drugs have been reported to reduce early postoperative feeding recovery (28). ERAS guidelines recommend the use of short-acting sedatives and avoidance of long-acting sedatives for postoperative recovery (15). Long-acting sedatives may reduce cognitive impairment in older patients and reduce early postoperative feeding recovery (15).

\section{Thromboembolic prophylaxis}

The incidence of venous thromboembolism after RC is $4-8 \%$. Patients who underwent neoadjuvant chemotherapy reported a higher risk of postoperative thromboembolism (29). Treatment with postoperative low-molecular-weight heparin significantly reduces venous thromboembolism after abdominal and pelvic surgery (30). ERAS guidelines recommended maintaining compression stocking and lowmolecular-weight heparin prophylaxis for at least 4 weeks after surgery (15).

\section{Minimally invasive surgery}

Minimally invasive surgery can reduce pain and blood loss with smaller incisions. It can also affect pain medication use and recovery time (31). However, RARC takes longer operation time than open RC but its advantages include smaller incision size, minimal blood loss, and pain. However, in terms of complications and morbidity, there 
was no significant difference between the two surgeries (32). In addition, long-term pneumoperitoneum and Trendelenburg position is a burden in elderly patients with cardiopulmonary disease.

\section{Resection-site drainage}

Generally, drainage of the incision after surgery has been considered to reduce the risk of infection at the surgical site and to identify problems such as urine leakage at the surgical site. However, the ERAS protocol recommends removing surgical drains as soon as possible (33). In colorectal surgery, early drain removal from the surgical site did not affect surgical outcomes (34). In the case of RC, there may be a difference in colorectal surgery because urine leakage may affect intestinal recovery; however, during RARC surgery it has recently been recommended to remove the drain on postoperative day 1 if there is no evidence of urine leakage (35).

\section{Preventing intraoperative hypothermia}

Prolonged abdominal surgery causes hypothermia in the patient. In colorectal surgery, prevention of intraoperative hypothermia reduces postoperative complications and shortens hospitalization for patients (36).

\section{Perioperative fluid management}

Hypervolemia or excess fluid replacement can cause low perfusion and postoperative ileus, which can increase with intestinal obstruction or related morbidity. It is important to maintain fluid balance to reduce this morbidity (37). Goaldirected fluid therapy optimizes blood flow using esophageal Doppler in colorectal surgery, and has been reported to reduce postoperative complications and hospitalization (37). Even in RC, this Doppler-optimized intraoperative fluid management alleviated the risk of intestinal obstruction, nausea and vomiting early in the surgery (38).

\section{Perioperative analgesia}

The ERAS guideline recommends a minimum of $72 \mathrm{~h}$ of thoracic epidural analgesia (EDA) rather than systemic opioids for pain management (15). In addition to pain reduction, EDA in colorectal surgery has been shown to reduce ileus, promote postoperative recovery, and reduce cardiopulmonary flatulence (39). In studies involving patients undergoing RC, chest EDA yielded functional results and pain relief, but prospective studies are lacking $(40,41)$. EDA is recommended at the T10 level. The optimal duration is 48 or $72 \mathrm{~h}$ after surgery. The use of minimal opioids and short-acting opioids based on fentanyl is recommended. A recent study of RARC with intracorporeal urinary diversion reported EDA can be routinely omitted (42). In addition, the regular administration of nonsteroidal antiinflammatory drugs, acetaminophen, is recommended (25).

\section{Urinary drainage}

The ERAS guideline recommends that transurethral catheters be removed on postoperative day one. Ureteral stents should be removed after 5 days postoperatively, but the evidence is not clear (15). Ureteral stents are beneficial for urine drainage and promotion of intestinal recovery, and to reduce metabolic acidosis (33). The optimal duration of postoperative ureteral stents is unknown; however, surveys show that the ureteral stent in most patients with ileal conduit can be removed within 2 weeks after surgery. In orthotopic neobladder, 70\% of respondents underwent removal of the ureteral stent within 2 weeks after surgery and $30 \%$ of respondents carried it for more than 2 weeks after surgery (35).

\section{Prevention of postoperative ileus, nausea and vomiting}

Postoperative nausea and vomiting (PONV) prophylaxis is indicated by opioid use, inhalation anesthetics, and nitrous oxide. Optimal management of fluid during surgery with esophageal Doppler has been reported to reduce PONV within $48 \mathrm{~h}$ after surgery (38). Prokinetic agents such as metoclopramide, antiemetics, dexamethasone, and propofol have been reported to prevent PONV $(38,43)$. In addition, insertion of the ureter stent may prevent PONV during uretero-ileal anastomosis (33). After RC, ileus is one of the most common complications, and is the main cause of delayed discharge. Postoperative ileus can lead to an imbalance in the patient's nutritional status, increase morbidity, and increase hospital stay $(44,45)$. Chewing gum has been reported to help prevent ileus. It has been reported to reduce the first flatus time and shorten the first bowel movement time $(46,47)$. Oral laxatives are also recommended for the early recovery of organs after surgery. Prophylactic oral laxatives can rapidly restore normal bowel movement postoperatively and shorten the time to first bowel movement (48). In addition, the administration of alvimopan, an opioid receptor antagonist, has been reported 
to facilitate early recovery of intestinal function after surgery and shorten the length of hospital stay (49). RARC is reported to restore bowel function faster than Open RC (31).

\section{Early oral feeding}

Early oral food intake is important in EARS and is known to improve body homeostasis and muscle function, reduce postoperative ileus, reduce infectivity and improve recovery $(50,51)$, There is no solid evidence of early oral food intake for RC. A meta-analysis of major abdominal surgeries reported that the group exposed to early food intake had a reduced complication rate and an increased rate of recovery. In addition, early oral food intake was reported to be beneficial in normalizing the intestinal time, such as time to flatus and time to first bowel movement (52). In colorectal surgery, early oral food intake was reported to reduce hospital stays without increasing morbidity $(53,54)$.

\section{Early mobilization}

Early mobilization in colorectal surgery shortens hospital stays (55). In addition, early mobilization after RC facilitates patients' ability to perform their daily activities (17). Early mobilization after surgery is known to reduce postoperative cardiopulmonary complications and prevent thromboembolism (56). It also reduces pain, increases muscle strength, reduces the incidence of intestinal obstruction, and promotes bowel activity (57).

\section{Studies evaluating the role of ERAS in RC}

Table 2 shows the outcomes following application of ERAS to recent RC surgery. The length of stay (LOS), complication rate, readmission rate and mortality for 30 or 90 days were assessed. The differences in the timing of bowel movement recovery and pain relief after ERAS were investigated. Dunkman et al. reported a decrease in LOS in patients undergoing RC combined with the ERAS protocol compared with those without ERAS (62). Tan et al. reported that RARC with ERAS decreased LOS compared with RARC without ERAS and RC without ERAS: The median LOS was 7,11 , and 17 days, respectively (65). In addition, several studies reported LOS decrease after ERAS by comparing the LOS between RC patients before and after ERAS protocol $(42,66,68,70,71,73,79)$. A meta-analysis also reported a decrease in LOS following the ERAS protocol, and reported a significant association between ERAS and LOS (78).

Most studies reported short-term complications after 30 and 90 days postoperatively, and analyzed the

Table 2 Studies evaluating the role of ERAS in radical cystectomy

\begin{tabular}{|c|c|c|c|c|c|c|}
\hline Study & Year & Patients & Design & $\begin{array}{l}\text { Operation } \\
\text { type }\end{array}$ & Intervention group & Outcomes \\
\hline $\begin{array}{l}\text { Tamhankar } \\
\text { et al. (58) }\end{array}$ & 2020 & 35 & Retrospective & $\begin{array}{l}\text { RARC + } \\
\text { IUD }\end{array}$ & ERAS & $\begin{array}{l}\text { Median LOS: } 8 \text { [4-30] days } \\
\text { Overall complication } 45.7 \% \text {, } \geq \text { grade } 3 \text { complication } 14.3 \% \\
\text { 90-day mortality: } 0 \%\end{array}$ \\
\hline $\begin{array}{l}\text { Ziegelmueller } \\
\text { et al. (60) }\end{array}$ & 2019 & 35 & $\begin{array}{l}\text { Prospective, } \\
\text { randomization }\end{array}$ & $\mathrm{RC}$ & $\begin{array}{l}\text { ERAS/conservative } \\
\text { regimen }\end{array}$ & $\begin{array}{l}\text { ERAS vs. conservative regimens: continence and CSS did } \\
\text { not differ }\end{array}$ \\
\hline $\begin{array}{l}\text { Kotov et al. } \\
(61)\end{array}$ & 2019 & 134 & Prospective & $\begin{array}{l}\mathrm{RC}+ \\
\mathrm{LRC}\end{array}$ & ERAS & $\begin{array}{l}\text { 90-day complication: } 70 \%, \geq \text { grade } 3 \text { complication: } 32 \% \text {, } \\
\text { 90-day mortality: } 11.9 \% \text {, LOS: } 12 \text { [9-16] days }\end{array}$ \\
\hline $\begin{array}{l}\text { Cheng et al. } \\
\text { (63) }\end{array}$ & 2019 & 512 & Retrospective & $\mathrm{RC}$ & ERAS & $\begin{array}{l}\text { ICU admission: } 6.4 \% \text {, median ICU day: } 3 \text { [0-32] days } \\
\text { Median LOS: } 11.5 \text { days (ICU), } 5 \text { days (non-ICU) }\end{array}$ \\
\hline
\end{tabular}

Table 2 (continued) 
Table 2 (continued)

\begin{tabular}{|c|c|c|c|c|c|c|}
\hline Study & Year & Patients & Design & $\begin{array}{l}\text { Operation } \\
\text { type }\end{array}$ & Intervention group & Outcomes \\
\hline $\begin{array}{l}\text { Zainfeld et al. } \\
\text { (64) }\end{array}$ & 2018 & 289 & Retrospective & $\mathrm{RC}$ & ERAS & $\begin{array}{l}\text { Median LOS: } 4 \text { days, } 30 \text {-day complication and } \\
\text { readmission: } 58.8 \% \text { and } 16.6 \%\end{array}$ \\
\hline Tan et al. (65) & 2018 & 304 & Prospective & $\begin{array}{l}\text { ORC }+ \\
\text { RARC }+ \\
\text { IUD }\end{array}$ & $\begin{array}{l}\text { ORC/RARC/RARC } \\
\text { with ERAS }\end{array}$ & $\begin{array}{l}\text { Median LOS: } 17 \text { [14-21] days/11 [8-15] days/7 [6-10] days } \\
\text { 90-day complication and readmission is lower in RARC } \\
\text { with EARS group }\end{array}$ \\
\hline $\begin{array}{l}\text { Semerjian } \\
\text { et al. (66) }\end{array}$ & 2018 & 110 & Retrospective & $\mathrm{RC}$ & $\begin{array}{l}\text { Pre-ERAS/ } \\
\text { post-ERAS }\end{array}$ & $\begin{array}{l}\text { Median LOS: } 8.5 \text { vs. } 5 \text { days, } \mathrm{P}<0.001 \\
\text { Overall complication, } 90 \text {-day readmission: no difference }\end{array}$ \\
\hline $\begin{array}{l}\text { Patel et al. } \\
(67)\end{array}$ & 2018 & 259 & Retrospective & $\mathrm{RC}$ & $\begin{array}{l}\text { Pre-ERAS/ } \\
\text { post-ERAS }\end{array}$ & LOS, 90-day complication and readmission: no difference \\
\hline $\begin{array}{l}\text { Matulewicz } \\
\text { et al. (70) }\end{array}$ & 2018 & 171 & Retrospective & $\mathrm{RC}$ & $\begin{array}{l}\text { Pre-ERAS/ } \\
\text { post-ERAS }\end{array}$ & $\begin{array}{l}\text { Median LOS: } 8.5 \text { vs. } 7 \text { days, } P=0.001 \text {, days to flatus: } 4 \text { vs. } \\
3 \text { days. } P<0.001 \text {, days to bowel movement: } 5 \text { vs. } 4 \text { days, } \\
P<0.001\end{array}$ \\
\hline Liu et al. (71) & 2018 & 260 & Retrospective & $\mathrm{RC}$ & $\begin{array}{l}\text { Pre-ERAS/ } \\
\text { post-ERAS }\end{array}$ & $\begin{array}{l}\text { Mean LOS: } 14.25 \text { vs. } 10.91, P=0.043,30 \text {-day complication } \\
\text { and readmission: no difference }\end{array}$ \\
\hline $\begin{array}{l}\text { Kukreja et al. } \\
(72)\end{array}$ & 2018 & 383 & Prospective & $\mathrm{RC}$ & $\begin{array}{l}\text { ERAS/traditional } \\
\text { care }\end{array}$ & $\begin{array}{l}\text { Reduced immediate postoperative symptom: pain, } \\
\text { drowsiness, dry mouth, disturbed sleep, interference with } \\
\text { functioning }\end{array}$ \\
\hline $\begin{array}{l}\text { Bazargani } \\
\text { et al. }(75)\end{array}$ & 2018 & 292 & Retrospective & $\mathrm{RC}$ & $\begin{array}{l}\text { Pre-ERAS/ } \\
\text { post-ERAS }\end{array}$ & $\begin{array}{l}\text { Median time to first flatus: } 2 \text { days, median LOS: } 4 \text { days } \\
\text { 30-day Gl complication: } 27 \% \text { vs. } 13 \%, P=0.003\end{array}$ \\
\hline $\begin{array}{l}\text { Djaladat et al. } \\
\text { (76) }\end{array}$ & 2017 & 169 & Retrospective & $\mathrm{RC}$ & ERAS & $\begin{array}{l}90 \text {-day major and minor complication: } 24.3 \% \text { and } 53.9 \% \\
90 \text {-day readmission: } 29.6 \%\end{array}$ \\
\hline $\begin{array}{l}\text { Baack et al. } \\
(77)\end{array}$ & 2017 & 200 & Retrospective & $\mathrm{RC}$ & $\begin{array}{l}\text { Pre-ERAS/ } \\
\text { post-ERAS }\end{array}$ & $\begin{array}{l}\text { Median LOS: } 8 \text { vs. } 5 \text { days, } \mathrm{P}<0.001 \\
\text { 90-day complication and readmission: no difference }\end{array}$ \\
\hline $\begin{array}{l}\text { Collins et al. } \\
(42)\end{array}$ & 2016 & 135 & Retrospective & $\mathrm{RC}$ & $\begin{array}{l}\text { Pre-ERAS/ } \\
\text { post-ERAS }\end{array}$ & $\begin{array}{l}\text { Median LOS: } 9 \text { [8-13] vs. } 8 \text { [6-10] days, } \mathrm{P}<0.001 \\
\text { 30-day complication, readmission and 90-day mortality: no } \\
\text { difference }\end{array}$ \\
\hline Xu et al. (78) & 2015 & 205 & Retrospective & $\mathrm{RC}$ & $\begin{array}{l}\text { ERAS/Traditional } \\
\text { care }\end{array}$ & Opioid per day: 4.9 vs. $20.67 \mathrm{mg}$ \\
\hline
\end{tabular}

GI, gastrointestinal; IUD, intracorporeal urinary diversion; IVLI, intravenous lidocaine infusion; LOS, length of hospital day; LRC, laparoscopic radical cystectomy; ORC, open radical cystectomy; RARC, robot-assisted radical cystectomy; RC, radical cystectomy; VTE, venous thromboembolism. 
overall and severe complications (grade 3 or higher). In a comparative study of patient groups before and after the ERAS protocol, most studies reported no differences in complications between the two groups $(42,66,67,69,71,79)$. However, Pang et al. reported a postoperative re-admission rate of $10 \%(\mathrm{P}=0.043)$ in the ERAS and non-groups (68). Bazargani et al. reported that the GI complications within 30 days after surgery were $14 \%$ lower in the group exposed to ERAS after surgery compared with the group exposed to ERAS preoperatively (75).

Several studies have also analyzed the recovery of bowel function after surgery $(62,69)$. Dunkman et al. reported that the day to first stool showed a significant difference of 5.8 and 4 days between the non-ERAS and the ERAS groups $(\mathrm{P}<0.001)$ (62). In addition, the first intake of solid food occurred 3.2 days in the ERAS group, which was 6 days shorter than in the group without ERAS $(\mathrm{P}<0.001)$. Palumbo et al. reported a significant difference in the passage of stool between $50 \%$ and $0 \%$ in the ERAS and the standard care groups after 3 days postoperatively $(\mathrm{P}<0.01)$ (69).

Further, Kukreja et al. reported that the ERAS-exposed group exhibited significantly less perioperative symptom burden, such as pain, drowsiness, dry mouth, disturbed sleep, and interference with functioning, compared with the group managed with traditional care (72). Xu et al. reported that the group managed with ERAS had significantly lower opioid usage than the group exposed to traditional care (78).

\section{Conclusions}

ERAS is an important treatment component in patients undergoing RC. The ERAS protocol is designed to avoid mechanical preparations and to improve postoperative recovery by minimizing fasting periods, and by promoting rapid dietary intake and mobilization after surgery. Several studies have shown that ERAS improves the recovery of RC patients. However, the high-level evidence supporting specific items in the ERAS guideline for RC patients is based on findings from colorectal surgery. Based on the differences between colorectal surgery and bladder resection and morbidity, additional randomized controlled studies or large prospective studies are needed to demonstrate the effectiveness of ERAS in patients undergoing RC.

\section{Acknowledgments}

Funding: None.

\section{Footnote}

Provenance and Peer Review: This article was commissioned by the Guest Editors (Ja Hyeon Ku, Ho Kyung Seo and Seok Ho Kang) for the series "Muscle-Invasive Bladder Cancer" published in Translational Andrology and Urology. The article has undergone external peer review.

Conflicts of Interest: The series "Muscle-Invasive Bladder Cancer" was commissioned by the editorial office without any funding or sponsorship. The authors have no conflicts of interest to declare.

Ethical Statement: The authors are accountable for all aspects of the work in ensuring that questions related to the accuracy or integrity of any part of the work are appropriately investigated and resolved.

Open Access Statement: This is an Open Access article distributed in accordance with the Creative Commons Attribution-NonCommercial-NoDerivs 4.0 International License (CC BY-NC-ND 4.0), which permits the noncommercial replication and distribution of the article with the strict proviso that no changes or edits are made and the original work is properly cited (including links to both the formal publication through the relevant DOI and the license). See: https://creativecommons.org/licenses/by-nc-nd/4.0/.

\section{References}

1. Kehlet H. Multimodal approach to control postoperative pathophysiology and rehabilitation. Br J Anaesth 1997;78:606-17.

2. Fearon KC, Ljungqvist $\mathrm{O}$, Von Meyenfeldt $M$, et al. Enhanced recovery after surgery: a consensus review of clinical care for patients undergoing colonic resection. Clin Nutr 2005;24:466-77.

3. Lassen K, Soop M, Nygren J, et al. Consensus review of optimal perioperative care in colorectal surgery: Enhanced Recovery After Surgery (ERAS) Group recommendations. Arch Surg 2009;144:961-9.

4. Cerantola Y, Valerio M, Persson B, et al. Guidelines for perioperative care after radical cystectomy for bladder cancer: Enhanced Recovery After Surgery (ERAS((R))) society recommendations. Clin Nutr 2013;32:879-87.

5. Wijk L, Udumyan R, Pache B, et al. International validation of Enhanced Recovery After Surgery Society 
guidelines on enhanced recovery for gynecologic surgery. Am J Obstet Gynecol 2019;221:237.e1-237.e11.

6. Tanious MK, Ljungqvist O, Urman RD. Enhanced Recovery After Surgery: History, Evolution, Guidelines, and Future Directions. Int Anesthesiol Clin 2017;55:1-11.

7. Mortensen K, Nilsson M, Slim K, et al. Consensus guidelines for enhanced recovery after gastrectomy: Enhanced Recovery After Surgery (ERAS(R)) Society recommendations. Br J Surg 2014;101:1209-29.

8. Melloul E, Hubner M, Scott M, et al. Guidelines for Perioperative Care for Liver Surgery: Enhanced Recovery After Surgery (ERAS) Society Recommendations. World J Surg 2016;40:2425-40.

9. Batchelor TJP, Rasburn NJ, Abdelnour-Berchtold E, et al. Guidelines for enhanced recovery after lung surgery: recommendations of the Enhanced Recovery After Surgery (ERAS(R)) Society and the European Society of Thoracic Surgeons (ESTS). Eur J Cardiothorac Surg 2019;55:91-115.

10. Aviles C, Hockenberry M, Vrochides D, et al.

Perioperative Care Implementation: Evidence-Based Practice for Patients With Pancreaticoduodenectomy Using the Enhanced Recovery After Surgery Guidelines. Clin J Oncol Nurs 2017;21:466-72.

11. Kiecolt-Glaser JK, Page GG, Marucha PT, et al. Psychological influences on surgical recovery. Perspectives from psychoneuroimmunology. Am Psychol 1998;53:1209-18.

12. Egbert LD, Battit GE, Welch CE, et al. Reduction of Postoperative Pain by Encouragement and Instruction of Patients. A Study of Doctor-Patient Rapport. N Engl J Med 1964;270:825-7.

13. Merandy K, Morgan MA, Lee R, et al. Improving Self-Efficacy and Self-Care in Adult Patients With a Urinary Diversion: A Pilot Study. Oncol Nurs Forum 2017;44:E90-100.

14. Ali NS, Khalil HZ. Effect of psychoeducational intervention on anxiety among Egyptian bladder cancer patients. Cancer Nurs 1989;12:236-42.

15. Gustafsson UO, Scott MJ, Hubner M, et al. Guidelines for Perioperative Care in Elective Colorectal Surgery: Enhanced Recovery After Surgery (ERAS((R))) Society Recommendations: 2018. World J Surg 2019;43:659-95.

16. Hollenbeck BK, Miller DC, Taub D, et al. Identifying risk factors for potentially avoidable complications following radical cystectomy. J Urol 2005;174:1231-7.

17. Jensen BT, Petersen AK, Jensen JB, et al. Efficacy of a multiprofessional rehabilitation programme in radical cystectomy pathways: a prospective randomized controlled trial. Scand J Urol 2015;49:133-41.

18. Thomsen T, Villebro N, Moller AM. Interventions for preoperative smoking cessation. Cochrane Database Syst Rev 2014;(3):CD002294.

19. Leow JJ, Gandaglia G, Sood A, et al. Readmissions after major urologic cancer surgery. Can J Urol 2014;21:7537-46.

20. Tonnesen H, Kehlet H. Preoperative alcoholism and postoperative morbidity. Br J Surg 1999;86:869-74.

21. Gregg JR, Cookson MS, Phillips S, et al. Effect of preoperative nutritional deficiency on mortality after radical cystectomy for bladder cancer. J Urol 2011;185:90-6.

22. $\mathrm{Xu} \mathrm{R}$, Zhao $\mathrm{X}$, Zhong $\mathrm{Z}$, et al. No advantage is gained by preoperative bowel preparation in radical cystectomy and ileal conduit: a randomized controlled trial of 86 patients. Int Urol Nephrol 2010;42:947-50.

23. Hashad MM, Atta M, Elabbady A, et al. Safety of no bowel preparation before ileal urinary diversion. BJU Int 2012;110:E1109-13.

24. Güenaga KF, Matos D, Wille-Jørgensen P. Mechanical bowel preparation for elective colorectal surgery. Cochrane Database Syst Rev 2011;(9):CD001544.

25. Adding C, Collins JW, Laurin O, et al. Enhanced recovery protocols (ERP) in robotic cystectomy surgery. Review of current status and trends. Curr Urol Rep 2015;16:32.

26. Bilku DK, Dennison AR, Hall TC, et al. Role of preoperative carbohydrate loading: a systematic review. Ann R Coll Surg Engl 2014;96:15-22.

27. Smith I, Kranke P, Murat I, et al. Perioperative fasting in adults and children: guidelines from the European Society of Anaesthesiology. Eur J Anaesthesiol 2011;28:556-69.

28. Walker KJ, Smith AF. Premedication for anxiety in adult day surgery. Cochrane Database Syst Rev 2009;(4):CD002192.

29. Alberts BD, Woldu SL, Weinberg AC, et al. Venous thromboembolism after major urologic oncology surgery: a focus on the incidence and timing of thromboembolic events after 27,455 operations. Urology 2014;84:799-806.

30. Tyson MD, Castle EP, Humphreys MR, et al. Venous thromboembolism after urological surgery. J Urol 2014;192:793-7.

31. Nix J, Smith A, Kurpad R, et al. Prospective randomized controlled trial of robotic versus open radical cystectomy for bladder cancer: perioperative and pathologic results. Eur Urol 2010;57:196-201.

32. Novara G, Catto JW, Wilson T, et al. Systematic review and cumulative analysis of perioperative outcomes and complications after robot-assisted radical cystectomy. Eur Urol 2015;67:376-401. 
33. Mattei A, Birkhaeuser FD, Baermann C, et al. To stent or not to stent perioperatively the ureteroileal anastomosis of ileal orthotopic bladder substitutes and ileal conduits? Results of a prospective randomized trial. J Urol 2008;179:582-6.

34. Karliczek A, Jesus EC, Matos D, et al. Drainage or nondrainage in elective colorectal anastomosis: a systematic review and meta-analysis. Colorectal Dis 2006;8:259-65.

35. Collins JW, Patel H, Adding C, et al. Enhanced Recovery After Robot-assisted Radical Cystectomy: EAU Robotic Urology Section Scientific Working Group Consensus View. Eur Urol 2016;70:649-60.

36. Azhar RA, Bochner B, Catto J, et al. Enhanced Recovery after Urological Surgery: A Contemporary Systematic Review of Outcomes, Key Elements, and Research Needs. Eur Urol 2016;70:176-87.

37. Giglio M, Manca F, Dalfino L, et al. Perioperative hemodynamic goal-directed therapy and mortality: a systematic review and meta-analysis with meta-regression. Minerva Anestesiol 2016;82:1199-213.

38. Pillai P, McEleavy I, Gaughan M, et al. A double-blind randomized controlled clinical trial to assess the effect of Doppler optimized intraoperative fluid management on outcome following radical cystectomy. J Urol 2011;186:2201-6.

39. Carli F, Kehlet H, Baldini G, et al. Evidence basis for regional anesthesia in multidisciplinary fast-track surgical care pathways. Reg Anesth Pain Med 2011;36:63-72.

40. Toren P, Ladak S, Ma C, et al. Comparison of epidural and intravenous patient controlled analgesia in patients undergoing radical cystectomy. Can J Urol 2009;16:4716-20.

41. Maffezzini M, Campodonico F, Capponi G, et al. Fast-track surgery and technical nuances to reduce complications after radical cystectomy and intestinal urinary diversion with the modified Indiana pouch. Surg Oncol 2012;21:191-5.

42. Collins JW, Adding C, Hosseini A, et al. Introducing an enhanced recovery programme to an established totally intracorporeal robot-assisted radical cystectomy service. Scand J Urol 2016;50:39-46.

43. López-Olaondo L, Carrascosa F, Pueyo FJ, et al. Combination of ondansetron and dexamethasone in the prophylaxis of postoperative nausea and vomiting. Br J Anaesth 1996;76:835-40.

44. Chang SS, Cookson MS, Baumgartner RG, et al. Analysis of early complications after radical cystectomy: results of a collaborative care pathway. J Urol 2002;167:2012-6.

45. Correia MI, da Silva RG. The impact of early nutrition on metabolic response and postoperative ileus. Curr Opin Clin Nutr Metab Care 2004;7:577-83.

46. Choi H, Kang SH, Yoon DK, et al. Chewing gum has a stimulatory effect on bowel motility in patients after open or robotic radical cystectomy for bladder cancer: a prospective randomized comparative study. Urology 2011;77:884-90.

47. Fitzgerald JE, Ahmed I. Systematic review and metaanalysis of chewing-gum therapy in the reduction of postoperative paralytic ileus following gastrointestinal surgery. World J Surg 2009;33:2557-66.

48. Zingg U, Miskovic D, Pasternak I, et al. Effect of bisacodyl on postoperative bowel motility in elective colorectal surgery: a prospective, randomized trial. Int J Colorectal Dis 2008;23:1175-83.

49. Lee CT, Chang SS, Kamat AM, et al. Alvimopan accelerates gastrointestinal recovery after radical cystectomy: a multicenter randomized placebo-controlled trial. Eur Urol 2014;66:265-72.

50. Lewis SJ, Andersen HK, Thomas S. Early enteral nutrition within $24 \mathrm{~h}$ of intestinal surgery versus later commencement of feeding: a systematic review and metaanalysis. J Gastrointest Surg 2009;13:569-75.

51. Schroeder D, Gillanders L, Mahr K, et al. Effects of immediate postoperative enteral nutrition on body composition, muscle function, and wound healing. JPEN J Parenter Enteral Nutr 1991;15:376-83.

52. Osland E, Yunus RM, Khan S, et al. Early versus traditional postoperative feeding in patients undergoing resectional gastrointestinal surgery: a meta-analysis. JPEN J Parenter Enteral Nutr 2011;35:473-87.

53. Behrns KE, Kircher AP, Galanko JA, et al. Prospective randomized trial of early initiation and hospital discharge on a liquid diet following elective intestinal surgery. J Gastrointest Surg 2000;4:217-21.

54. Fearon KC, Luff R. The nutritional management of surgical patients: enhanced recovery after surgery. Proc Nutr Soc 2003;62:807-11.

55. Vlug MS, Wind J, Hollmann MW, et al. Laparoscopy in combination with fast track multimodal management is the best perioperative strategy in patients undergoing colonic surgery: a randomized clinical trial (LAFA-study). Ann Surg 2011;254:868-75.

56. Patel HR, Cerantola Y, Valerio M, et al. Enhanced recovery after surgery: are we ready, and can we afford not to implement these pathways for patients undergoing 
radical cystectomy? Eur Urol 2014;65:263-6.

57. Klein S, Kinney J, Jeejeebhoy K, et al. Nutrition support in clinical practice: review of published data and recommendations for future research directions. Summary of a conference sponsored by the National Institutes of Health, American Society for Parenteral and Enteral Nutrition, and American Society for Clinical Nutrition. Am J Clin Nutr 1997;66:683-706.

58. Tamhankar AS, Ahluwalia P, Patil SR, et al. Implementation of ERAS protocol in robot-assisted radical cystectomy with intracorporeal ileal conduit urinary diversion: An outcome analysis beyond the learning curve. Indian J Urol 2020;36:37-43.

59. Ghoreifi A, Van Horn CM, Xu W, et al. Urinary tract infections following radical cystectomy with enhanced recovery protocol: A prospective study. Urol Oncol 2020;38:75.e9-75.e14.

60. Ziegelmueller BK, Jokisch JF, Buchner A, et al. LongTerm Follow-Up and Oncological Outcome of Patients Undergoing Radical Cystectomy for Bladder Cancer following an Enhanced Recovery after Surgery (ERAS) Protocol: Results of a Large Randomized, Prospective, Single-Center Study. Urol Int 2020;104:55-61.

61. Kotov SV, Khachatryan AL, Kotova DP, et al. Analysis of the results of ERAS protocol in real-life clinical practice AFTER radical cystectomy (the first prospective multicenter study in Russia). Urologiia 2019;(6):60-6.

62. Dunkman WJ, Manning MW, Whittle J, et al. Impact of an enhanced recovery pathway on length of stay and complications in elective radical cystectomy: a before and after cohort study. Perioper Med (Lond) 2019;8:9.

63. Cheng KW, Shah A, Bazargani S, et al. Factors influencing ICU admission and associated outcome in patients undergoing radical cystectomy with enhanced recovery pathway. Urol Oncol 2019;37:572.e13-572.e19.

64. Zainfeld D, Chen J, Cai J, et al. The impact of patientrelated nonmodifiable factors on perioperative outcomes following radical cystectomy with enhanced recovery protocol. Ther Adv Urol 2018;10:393-401.

65. Tan WS, Tan MY, Lamb BW, et al. Intracorporeal robotassisted radical cystectomy, together with an enhanced recovery programme, improves postoperative outcomes by aggregating marginal gains. BJU Int 2018;121:632-9.

66. Semerjian A, Milbar N, Kates M, et al. Hospital Charges and Length of Stay Following Radical Cystectomy in the Enhanced Recovery After Surgery Era. Urology 2018;111:86-91.
67. Patel SY, Garcia Getting RE, Alford B, et al. Improved Outcomes of Enhanced Recovery After Surgery (ERAS) Protocol for Radical Cystectomy with Addition of a Multidisciplinary Care Process in a US Comprehensive Cancer Care Center. World J Surg 2018;42:2701-7.

68. Pang KH, Groves R, Venugopal S, et al. Prospective Implementation of Enhanced Recovery After Surgery Protocols to Radical Cystectomy. Eur Urol 2018;73:363-71.

69. Palumbo V, Giannarini G, Crestani A, et al. Enhanced Recovery After Surgery Pathway in Patients Undergoing Open Radical Cystectomy Is Safe and Accelerates Bowel Function Recovery. Urology 2018;115:125-32.

70. Matulewicz RS, Patel M, Jordan BJ, et al. Transversus Abdominis Plane Blockade as Part of a Multimodal Postoperative Analgesia Plan in Patients Undergoing Radical Cystectomy. Bladder Cancer 2018;4:161-7.

71. Liu B, Domes T, Jana K. Evaluation of an enhanced recovery protocol on patients having radical cystectomy for bladder cancer. Can Urol Assoc J 2018;12:421-6.

72. Kukreja JB, Shi Q, Chang CM, et al. Patient-Reported Outcomes Are Associated With Enhanced Recovery Status in Patients With Bladder Cancer Undergoing Radical Cystectomy. Surg Innov 2018;25:242-50.

73. Frees SK, Aning J, Black P, et al. A prospective randomized pilot study evaluating an ERAS protocol versus a standard protocol for patients treated with radical cystectomy and urinary diversion for bladder cancer. World J Urol 2018;36:215-20.

74. Bazargani ST, Ghodoussipour S, Tse B, et al. The association between intraoperative fluid intake and postoperative complications in patients undergoing radical cystectomy with an enhanced recovery protocol. World J Urol 2018;36:401-7

75. Bazargani ST, Djaladat H, Ahmadi H, et al. Gastrointestinal Complications Following Radical Cystectomy Using Enhanced Recovery Protocol. Eur Urol Focus 2018;4:889-94.

76. Djaladat H, Katebian B, Bazargani ST, et al. 90Day complication rate in patients undergoing radical cystectomy with enhanced recovery protocol: a prospective cohort study. World J Urol 2017;35:907-11.

77. Baack Kukreja JE, Kiernan M, Schempp B, et al. Quality Improvement in Cystectomy Care with Enhanced Recovery (QUICCER) study. BJU Int 2017;119:38-49.

78. Xu W, Daneshmand S, Bazargani ST, et al. Postoperative Pain Management after Radical Cystectomy: Comparing Traditional versus Enhanced Recovery Protocol Pathway. J 
Urol 2015;194:1209-13.

79. Giannarini G, Crestani A, Inferrera A, et al. Impact of enhanced recovery after surgery protocols versus standard of care on perioperative outcomes of radical cystectomy: a systematic review and meta-analysis of comparative studies. Minerva Urol Nefrol 2019;71:309-23.

Cite this article as: Sung LH, Yuk HD. Enhanced recovery after surgery of patients undergoing radical cystectomy for bladder cancer. Transl Androl Urol 2020;9(6):2986-2996. doi: 10.21037/tau.2020.03.44 